\title{
Modelling travelers' appraisal of ridepooling service characteristics with a discrete choice experiment
}

\author{
Alexandra König (i) and Jan Grippenkoven
}

\begin{abstract}
Background: Ridepooling services have been predicted a bright future since they promise a flexible and usercentered mobility service. However, there is a research gap in examining the travelers' perception of ridepooling service characteristics since findings concerning fixed-scheduled public transport are hardly transferable.

Methods: In order to shed some light on the human factors of ridepooling services a Discrete Choice Experiment $(N=410)$ was performed to identify travelers' preferences concerning ridepooling's service features. The study thereby focusses on the effect of trip purpose on the appraisal of the service attributes. Based on a literature review and a focus group six attributes of the operational concept were determined: fare, walking distance to the pick-up point, time of booking in advance, shift of departure time, travel time and information.

Results: The results underline that all of the six attributes significantly affected choice behavior. The appraisal of the service characteristics differed depending on the presented trip purpose. The willingness to pay was calculated for each service characteristics. The results give guidance for the user-centered design and operation of ridepooling systems that meet the requirements of the prospective passengers and thus facilitate behavioral shifts towards more sustainable mobility systems.
\end{abstract}

Keywords: Digitalized transport, Discrete choice experiment, Passenger perspective, Mobility on demand, Shared mobility

\section{Introduction - benefits of Ridepooling}

In the light of the steadily increasing number of passenger transport by private car [1] the development of shared mobility solutions has become an important field for research and transport providers [2]. Recent simulation studies have shown that the number of vehicles in cities could be reduced to a small proportion of nowadays vehicle fleet by the deployment of a shared (autonomous) vehicle fleet that pools ride requests of travelers and thus contribute to a reduction of traffic volume and the related emissions [1, 3, 4]. A variety of new mobility services is emerging within the range between conventional public transport and individual transport, facilitated by the rapid growth of information technology and digitalization [5]. Ridepooling concepts

\footnotetext{
* Correspondence: alexandra.koenig@dlr.de

Institute of Transportation Systems, German Aerospace Center (DLR e.V.), Lilienthalplatz 7, 38108 Braunschweig, Germany
}

provide on demand public transport services without fixed schedules and predefined stops by using digital booking and intelligent matching algorithms to pool the routes of passengers that are heading the same direction [6]. For passengers, ridepooling services provide flexible and personalized mobility by adapting time and pick-up point of the ride to the actual needs of the travelers [1]. Ridepooling schemes have existed for decades under the name of demand-responsive transport (DRT) in rural areas. A factor that counteracted a widespread operation of DRT services was the disproportionate effort that had to be invested by the users for booking and for service providers for route planning and management [7]. Nowadays, the rapid development and spread of information technology enables improved service efficiency and advances the provision of mobility on demand [8].

A large number of ridepooling services were launched during the last years, like Kutsuplus in Helsinki [9] or ioki in Hamburg ([10], July 16). 
However, those services are in most cases not accompanied by sufficient scientific research [11]. As Tsafarakis et al. [12] state, research still knowns little about the complexity of users' preferences regarding new mobility services, especially with regard to innovations in public transport. There is little information about how these new digitalized and flexible mobility services are used and how they may affect travel behavior, which is posing challenges for transport planners and researchers [11]. The article builds up on a related work by the authors concerning urban residents' appraisal of ridepooling systems and the associated service attributes [13]. The study that focused on city dwellers only, assessed the relative importance of the service characteristics for the participants' appraisal of the ridepooling service by addressing the research question: "door-to-door-service or fare?" The study found that the answer to the question depends on the sociodemographic factors of the person considered while fare was the most important service characteristic for younger individuals, elderly paid more attention to short walking distances to the pick-up point [13]. Yet, the study leaves the question open whether the findings can be transferred to a broader population. Furthermore, the prior study lacks an in-depth preference measurement based on regression analysis and willingness to pay assessment.

Before launching another ridepooling service there is a clear need for comprehensive research on the factors that affect the adoption of such systems. Hence, the study of travelers' requirements concerning ridepooling services is a necessary precondition for a user-centered design of ridepooling service concepts and their adoption. This article was developed on the basis of limited findings concerning travelers' preferences regarding ridepooling service concepts and the need to study users' preferences concerning innovations in public transport [12]. In order to address this research gap the article pursues three goals:

- To identify which service characteristics of ridepooling services affect travelers' appraisal of the ridepooling system.

- To examine the effects of trip purpose on the choice behavior of prospective users.

- To assess the prospective users' willingness to pay for different service characteristics of ridepooling systems.

\section{Literature review}

A literature review was conducted to determine the factors that have proven to affect travelers' appraisal of service characteristics of fixed-scheduled bus transport and thus might affect travelers' perception of a ridepooling's service concept. Therefore, attributes concerning the vehicle concept and the stop environment were not focus of the literature review. Regarding the limited number of empirical results concerning the operational service concept of ridepooling, the literature review was extended by studies on fixed-scheduled bus transport. In summary, the literature review revealed the importance of ten recurring attributes on travelers' appraisal of the service concept of public transport as shown in the Table 1.

Since ridepooling services are in large parts very different from fixed-scheduled public transport, the transferability of study results concerning travelers' appraisal of fixed-scheduled public transport service characteristics to new digitalized transport services is limited. For instance, as shown in Table 1, several studies emphasize the importance of reliability and punctuality for travellers' appraisal of public transport systems [14, 22-25]. For ridepooling systems, punctuality is presumably still important. However, in such flexible mobility services the criterion of punctuality will rather be related to a dynamic prognosis of the arrival time of a vehicle than to a fixed schedule determined to fixed stops.

Further service characteristics that have been proven to affect travelers' appraisal of public transport services like service frequency [21], speed [14] and service provision hours [15] have to be adapted to ridepooling concepts that waive fixed service elements in favour of flexible demand-responsive service elements. In the light of the absence of a fixed time schedule and route plan for ridepooling concepts travelers' information needs concerning the flexible route and the time of arrival among others are supposed to increase.

The timely and spatial flexibility of ridepooling schemes is expected to be attractive for certain trip purposes whereas the system immanent dynamic of service is supposed to be perceived as a critical factor for timely fixed trip. Since factors like the experience of time pressure and the need for punctuality strongly depend on the trip purpose, the contextual factor of trip purpose is supposed to strongly affect the travelers' appraisal of the ridepooling service characteristics. Therefore trip purpose might play an important role in the assessment and adoption of the demand-responsive mobility concept. The importance of trip purpose on the modal choice and value of travel time was emphasized before in literature concerning public transport [27, 29] as well as new mobility concepts like autonomous driving [30]. Thus, trip characteristics like time pressure have to be considered when analysing travelers' appraisal of ridepooling. 
Table 1 Results of literature review concerning attributes affecting travelers' perception of bus service quality

\begin{tabular}{|c|c|}
\hline Attributes & Sources \\
\hline $\begin{array}{l}\text { Reliability/ on-time performance/ punctuality/ } \\
\text { waiting time/ regularity/ timeliness }\end{array}$ & $\begin{array}{l}\text { Beirão and Cabral [14], Bourgeat [15, 16], Dell'Olio, Ibas and Cecin [16], De Oña, De Oña, Eboli, and } \\
\text { Mazzulla [17], De Oña, de Oña, Eboli, Forciniti, and Mazzulla [18], Diab, van Lierop, and El-Geneidy [19], } \\
\text { Eboli and Mazzulla [20], Eboli and Mazzulla [50], Hansson et al. [21], Hensher and Prioni [22]; Jianrong et al. [23] } \\
\text { Paulley et al. [24], Redman et al. [25], Tyrinopoulos and Antoniou [26], Tyrinopoulos and Antoniou [27] }\end{array}$ \\
\hline Frequency & $\begin{array}{l}\text { Bourgeat [15], De Oña et al. [17], Eboli and Mazzulla [20], Eboli and Mazzula [50], Hansson et al. [21], } \\
\text { Hensher and Prioni [22], Knapp (1997), Mazzulla and Eboli [28], Redman et al. [25], Tyrinopoulos and } \\
\text { Antoniou [26] }\end{array}$ \\
\hline Travel time/ speed/headway/time & $\begin{array}{l}\text { Beirão and Cabral [14], Bourgeat [15], De Oña et al. [17], De Oña et al. [18], Diab et al. [19], Hansson } \\
\text { et al. [21], Hensher and Prioni [22], Jianrong et al. [23], Knapp [51](1998), Redman et al. [25] }\end{array}$ \\
\hline Fare/price & $\begin{array}{l}\text { De Oña et al. [17], Eboli and Mazzulla [20], Hansson et al. [21], Hensher and Prioni [22], Jianrong et al. } \\
\text { [23], Knapp [51](1998), Paulley et al. [24], Redman et al. [25], Tyrinopoulos and Antoniou [26] }\end{array}$ \\
\hline Information provision/real-time information & $\begin{array}{l}\text { Beirão and Cabral [14], Bourgeat [15], De Oña et al. [17], Eboli and Mazzulla [50], Hansson et al. [21], } \\
\text { Hensher and Prioni [22], Mazzulla and Eboli [28], Paulley et al. [24], Redman et al. [25], Tyrinopoulos } \\
\text { and Antoniou [26], Tyrinopoulos and Antoniou [27] }\end{array}$ \\
\hline $\begin{array}{l}\text { Walking time to access/ proximity of stops/ } \\
\text { access and egress time }\end{array}$ & $\begin{array}{l}\text { Bourgeat [15], De Oña et al. [17], Eboli and Mazzulla [20]; Hensher and Prioni [22]; Paulley et al. [24], } \\
\text { Jianrong et al. [23], Tyrinopoulos and Antoniou [26] }\end{array}$ \\
\hline Number of stops & Knapp [51](1998), Mazzulla and Eboli [28] \\
\hline $\begin{array}{l}\text { Service provision hours/ operating hours/ } \\
\text { operating period/ last bus }\end{array}$ & Bourgeat [15], De Oña et al. [17], Knapp [51](1998), Tyrinopoulos and Antoniou [26] \\
\hline Network coverage & Tyrinopoulos and Antoniou [26] \\
\hline $\begin{array}{l}\text { Connectability/ Number and quality of } \\
\text { interchanges/Integration of network }\end{array}$ & Beirão and Cabral [14], De Oña et al. [17], De Oña et al. [18], Hansson et al. [21], Paulley et al. [24] \\
\hline
\end{tabular}

\section{Methodology}

\subsection{Discrete choice experiment to model travelers'} preferences

To address the stated research aims a Discrete Choice Experiment (DCE) was applied [31]. DCE bases on the Random Utility Theory (RUT) and proposes that individuals strive for utility maximization [31]. In DCE, the decisionmaker is confronted with choice sets that consist of different alternatives, which are characterized by a set of attributes. The relative importance of the attributes is elicited by presenting a series of choice sets with varying attributes' levels to the individual [32]. Due to their strengths in eliciting preferences DCE are applied in a considerable number of research domains like transportation [30].

\subsection{Selection of attributes and levels for DCE}

Literature outlines the importance of a comprehensive process for the definition of attributes of a choice experiment since the results highly depend on the selected attributes [32]. A two-stepped method was chosen for identifying attributes and corresponding levels as proposed by Dell'Olio et al. [16]. Based on the identified attributes of a literature review (Table 1), a focus group with 9 participants (female $=6, M=51.67$ years, $S D=22.5$ years) was conducted to validate the results of the literature review, to identify and include additional attributes relevant to ridepooling services and to exclude irrelevant attributes [33]. Furthermore, maximum acceptable levels, so called knock out criteria were assessed [34] and appropriate terms for the attributes were specified that correspond to the actual vocabulary of the prospective users [32].

For selecting the final attributes and levels for the DCE the guidelines of Weiber and Mühlhaus [34] were considered. Out of the ten attributes identified in the literature review frequency, service provision hours, network coverage and number of stops were excluded from further investigation since ridepooling systems are not based on a fixed timetable. Reliability was renamed shift of departure time since there is no predefined schedule in ridepooling systems. Shift of departure was defined as the shift of the actual pickup time caused by the ad hoc access of further passengers. Time of booking was added as attribute because the service concept of ridepooling requires a certain time interval of booking a ride before being picked up in contrast to the conventional forms of public transport. This attribute describes the minimal number of minutes required to book a ride before departure. The attribute travel time describes the total duration of the ride that might be prolonged by a detour due to the access and egress of other passengers. Information provision proved to be an important attribute for travelers' perception of bus transport and is supposed to be an important attribute of ridepooling concepts as well. The three levels of information provision differ in the quantity and real-time of information provided: 1) None: No information about the 
Table 2 Final attributes and corresponding levels used for DCE

\begin{tabular}{|c|c|c|c|c|c|c|c|}
\hline & & \multicolumn{6}{|l|}{ Attribute } \\
\hline & & Time of booking (min) & Walking distance $(\mathrm{m})$ & Shift of departure (min) & Travel time (min) & Information provision & Fare $(€)$ \\
\hline \multirow[t]{4}{*}{ Level } & 1 & 5 & 0 & 0 & 10 & None & 2.50 \\
\hline & 2 & 10 & 300 & 10 & 20 & Few & 3.00 \\
\hline & 3 & 30 & 500 & 20 & 30 & Much & 3.50 \\
\hline & 4 & & & & & & 4.00 \\
\hline
\end{tabular}

details of his journey are provided, 2) Few: the traveler receives few information about the journey, e.g. approximate time corridor of arrival, 3) Much: the user is provided with detailed and real-time information about the journey, e.g. map with route and realtime arrival time. Table 2 lists the final set of attributes and their corresponding levels used for DCE.

\subsection{Experimental choice design}

A fractional factorial design according to Aizaki, Nakatani, and Sato [35] was used to reduce the total number of possible ridepooling schemes to a subset of 24 choice sets as respondents can handle about 30 choice situations [36]. The study was performed as an online survey using the software SosciSurvey [37].

The respondents were introduced to one of two ridepooling scenarios (between-subjects-design): 1) a shopping trip to the city center on a weekday's afternoon with the trip purpose to buy a gift card and 2) a doctor's appointment at a weekday's afternoon. Since this scenario indicated a fixed appointment, time pressure was supposed to be higher than in the shopping scenario. The distance of both rides was set to $5 \mathrm{~km}$. As proposed by BahamondeBirke, Navarro, and de Dios Ortúzar [38] respondents were offered a none-of-these option to avoid a forced choice. Each choice set consisted of two alternatives and the opt-out option (Fig. 1). Before presenting the 24 choice sets in random order, the six attributes and levels were introduced to the participants with the help of graphical and textual descriptions.

\subsection{Data analysis}

Data were analyzed with the help of Mixed Multinominal Logit (MMNL, [39]) that represents the current state of the art for modelling DCE [40, 41]. MMNL differ from Multinominal Logit (MNL) because of the inclusion of random coefficients that are drawn from a cumulative distribution function arising from taste heterogeneity in a population [39]. MMNL recurrently result in a substantial improvement of fit over the MNL model because of the increased explanatory power of the specification [41]. MMNL represent a mixture of alternative-specific and case-specific regressors and account for the panel structure of the data [40]. Since MMNL does not demand the independence from irrelevant alternatives and account for correlations in unobserved utility panel data can be analyzed that base on the repeated choices of the decisionmakers [39]. MMNL is consistent with Random Utility Theory (RUT, [31]). RUT proposes that individuals will choose the alternative with the highest subjective utility $U$ that is described as the sum of an observed component $V$ and a residual component $e$. As shown in (1), the observed component of utility $V$ that represents the overall worth of an alternative $j$ is defined by the sum of the part-worths $\beta$ of its attributes where $x_{n s j k}$ is a vector of $k$ attributes [36]. Those parth-worths $\beta$ are preference weights that represent the contribution of the attribute to the utility of an alternative.

$$
V_{n s j}=\sum_{k=1}^{K} \stackrel{\tilde{A}}{O_{k}} x_{n s j k}
$$

\section{Which alternative would you choose?}

Alternative 1

Walking distance: $300 \mathrm{~m}$

Fare: $2.50 €$

Shift of departure: $+20 \mathrm{~min}$

Travel time: $20 \mathrm{~min}$

Information: much

Time of booking: $30 \mathrm{~min}$

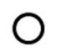

Alternative 2

Walking distance: $0 \mathrm{~m}$

Fare: $4.00 €$

Shift of departure: $+0 \mathrm{~min}$

Travel time: $20 \mathrm{~min}$

Information: much

Time of booking: $30 \mathrm{~min}$

O

None of these

$\mathrm{O}$

Fig. 1 Example of a choice set of the DCE (translated from German) 
MMNL was performed with the statistical software $R$ [42] using the mlogit function [43].

\subsection{Sample description}

After the exclusion of 111 respondents (21.3\%) that took less than two minutes to read the instructional pages the final sample size was $N=410$. The sample was characterized by a mean age of 45.3 years $(S D=17.2$ years) and consisted of slightly more men $(n=234,57.1 \%)$ than women ( $n=166,40.5 \%$, rest missing). See Table 3 for a detailed description of the sample. The participants came from all over Germany, with a high share of respondents living in the highly-populated states of Lower Saxony (20.2\%), Baden-Wurttemberg (12.9\%) and North-Rhine Westphalia (11.2\%). A total of $88.8 \%$ had a driver's license and $81.2 \%$ owned a car in their household. The majority of the respondents declared that they had heard about demand-responsive-transport-systems
(79.0\%) and $17.9 \%$ stated to have used such a transport system at least once in their life.

\section{Results}

\subsection{Model specification}

A total of 29,520 observations (410 respondents $\times 3$ alternatives $\times 24$ choice sets) were incorporated in the estimation of the model. The opt-out alternative was treated as the reference alternative within the model. The panel dimension of the data was taken into account by adding an argument to the model.

The assumptions for logistic regression were checked. The model including all of the six attributes revealed a high model fit as shown by McFadden $R^{2}=0.29916$ that lies within the required range between 0.2 and 0.4 [39]. The model's log-likelihood value was -7257.9 and the likelihood ratio test was $X^{2}=6196.1(p<.001)$. The Akaike Information Criterion was $A I C=14,543.72$ [36]. For each

Table 3 Sociodemographic characteristics of the sample $(N=410)$

\begin{tabular}{|c|c|c|c|}
\hline Sociodemographic variable & Characteristics & $\mathrm{n}$ & $\%$ \\
\hline \multirow[t]{3}{*}{ Gender } & Male & 234 & 57.1 \\
\hline & Female & 166 & 40.5 \\
\hline & Missing & 10 & 2.4 \\
\hline \multirow[t]{5}{*}{ Age } & $<30$ years & 96 & 23.4 \\
\hline & $30-44$ years & 107 & 26.1 \\
\hline & $45-59$ years & 100 & 24.4 \\
\hline & $>=60$ years & 101 & 24.6 \\
\hline & Missing & 6 & 1.5 \\
\hline \multirow[t]{5}{*}{ Size of residence (number of inhabitants) } & $<10.000$ & 88 & 21.4 \\
\hline & $10.000-50.000$ & 83 & 20.2 \\
\hline & $50.000-500.000$ & 158 & 38.6 \\
\hline & $>500.000$ & 74 & 18.1 \\
\hline & Missing & 5 & 1.2 \\
\hline \multirow[t]{6}{*}{ Highest educational level } & No educational qualification/still in education & 5 & 1.2 \\
\hline & Secondary school certificate & 46 & 11.2 \\
\hline & High school graduation & 94 & 22.9 \\
\hline & Vocational training & 39 & 9.5 \\
\hline & University degree & 220 & 53.7 \\
\hline & Missing & 4 & 1.0 \\
\hline \multirow[t]{8}{*}{ Employment status } & Full-time & 186 & 45.4 \\
\hline & Part-time & 47 & 11.5 \\
\hline & Unemployed & 7 & 1.7 \\
\hline & Retired & 80 & 19.5 \\
\hline & In education & 73 & 17.8 \\
\hline & Temporary out of work & 9 & 2.2 \\
\hline & Home-maker & 2 & 0.5 \\
\hline & Missing & 4 & 1.0 \\
\hline
\end{tabular}


Table 4 Results of mixed multinominal logistic regression

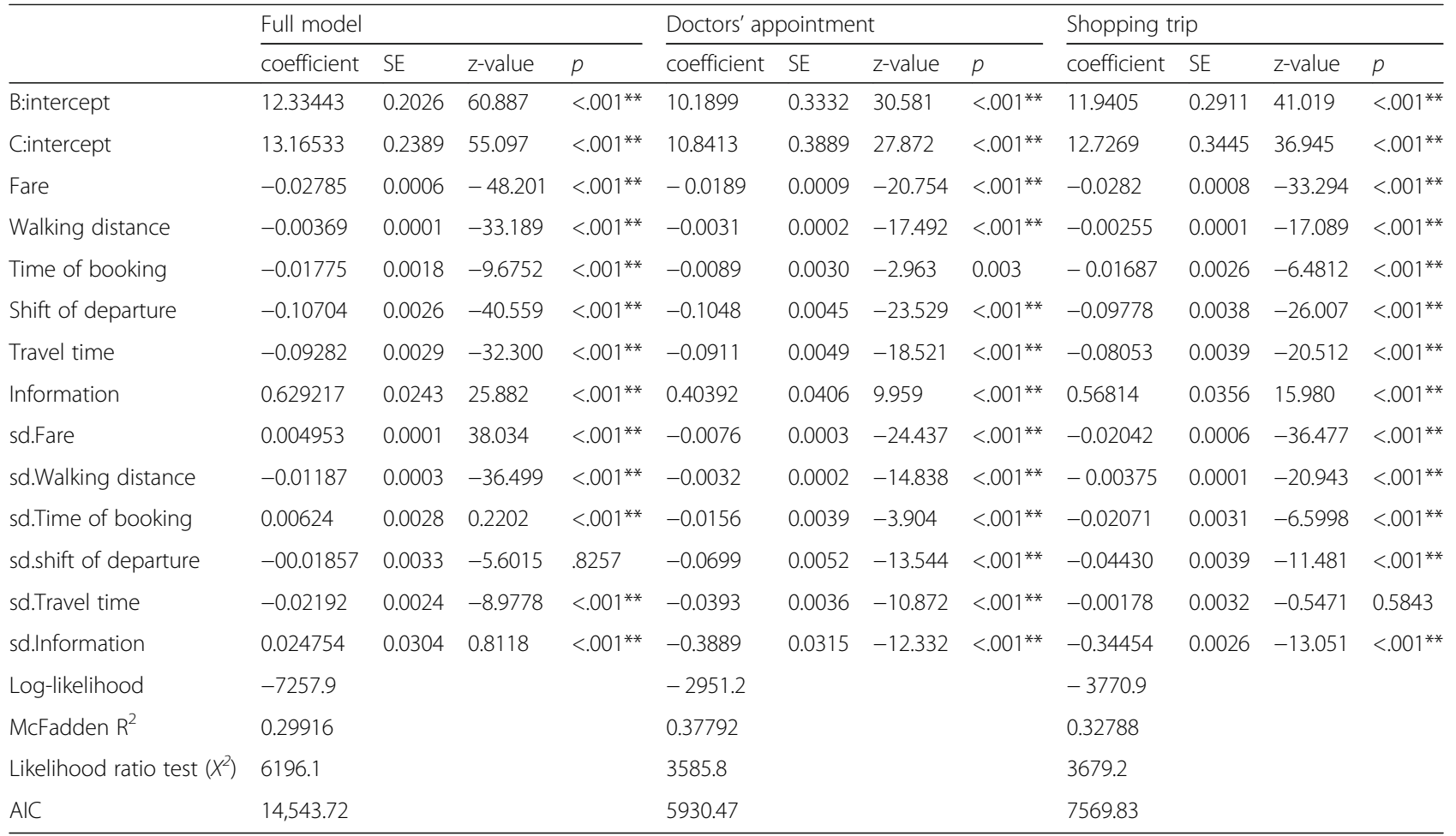

Notes $\beta=$ coefficient, $S E=$ standard error coefficient $p=p$-value, ${ }^{* *}=p<.001$

of the scenarios a separate model was computed. The three models (full model, shopping scenario and doctor's appointment scenario) are presented in Table 4.

\subsection{Preference measurement}

Table 4 shows the results of MMNL. The coefficients reflect the attributes' contributions to the overall utility [36]. For the full model, all coefficients significantly contributed to the overall utility as shown by a significant $\mathrm{p}$ value of $\mathrm{p}<.05$. Apparently, the respondents' choice is based strongly on all of the six service attributes. As shown in Table 4, respondents are attentive to the fare of the offered service $(B=-0.0279, \mathrm{p}<.001)$. As shown by the negative sign, the overall utility of the ridepooling service decreases when price increases. Furthermore, respondents are very sensitive to increasing walking distances $(\beta=-0.0037, \mathrm{p}<.001)$, shifts of departure $(\beta=-$ $0.107, \mathrm{p}<.001)$, a prolongation of travel time $(\beta=-$ $0.0928, \mathrm{p}<.001)$ and a higher lead time for bookings $(ß=-0.0177, p<.001)$. The positive value of the regression coefficient of the attribute information $(\beta=0.6292$, $\mathrm{p}<.001$ ) indicates a conducive impact of a better information provision on the respondents' appraisal of the ridepooling systems.

The standard deviations of each coefficient, expect shift of departure are highly significant, indicating that these coefficients vary in the population. This implies that there is a substantial amount of heterogeneity in the preferences for the various service attributes [44].

\subsection{Effect of trip purpose on choice behavior}

The trip purpose had an impact on the choice behavior of the respondents as shown by the comparison of the two models in Table 2. The AIC for the model regarding the shopping scenario was 7569.833 whereas the AIC for the model concerning the doctor's appointment was 5930.466. Thus, the model for the shopping scenario results in less information loss than the model concerning the doctor's scenario.

As shown by a higher value of the coefficients, respondents that were confronted with the scenario doctor's appointment showed to be more attentive to the attributes travel time $\left(\beta_{\text {travel time:trip purpose_doctor }}=-0.09108\right.$, $p<.001)$ and shift of departure $\left(\beta_{\text {shift of departure:trip purpo- }}\right.$ sedoctor $=-0.1048, p<.001)$ than respondents that were requested to imagine a shopping trip ( $\beta_{\text {travel time }}$ trip purpose_shopping $=-0.0805, p<.001 ; \beta$ shift of departure:trip purpose_shopping $=-0.0978, p<.001)$. The interaction effect for trip purpose and travel time $\left(\beta_{\text {travel time:trip purpose }}=-\right.$ 0.0136, $z=-3.008, p=.002$ ), as well as trip purpose and shift of departure was significant $\left(\beta_{\text {departure time:trip pur- }}\right.$ pose $=-0.0252, z=-5.4067, p<.001)$. Furthermore, respondents that envisioned a doctor's appointment as trip purpose were more sensitive to an increase in walking 
distance to the pick-up point $\left(\beta_{\text {walking distance:trip purpose_- }}\right.$ doctor $=-0.0031, p<.001, \beta_{\text {walking distance:trip purpose_shop- }}$ ping $=-0.0026, p<.001)$. The interaction effect was significant $\left(\beta_{\text {walking distance:trip purpose }}=0.0009, z=4.535\right.$, $p<.001)$. The interaction terms concerning trip purpose and fare $\left(\beta_{\text {fare:trip purpose }}=0.0001, z=0.2301, p=.818\right)$ as well as trip purpose and booking time $\left(\beta_{\text {booking time:trip }}\right.$ purpose $=-0.0014, z=-0.3885, p=.698)$ and trip purpose and information $\left(\beta_{\text {information:trip purpose }}=-0.057, z=-\right.$ $1.211, p=.226)$ were not significant. Thus, no effect of trip purpose on the attributes fare, booking time and information was proven.

\subsection{Willingness to pay estimation}

The willingness to pay (WTP) for each attribute was calculated by estimating the ratio of the attribute's coefficient to the price coefficient [41]. Table 5 compares the WTP of the five attributes regarding the trip purpose. As shown here, the respondents' willingness to pay for an improvement in the quality of service differed depending on the trip purpose. Respondents that pictured the doctor's appointment are willing to pay 12 cent extra for a pick up point that is $100 \mathrm{~m}$ closer compared to a WTP of 9 cent per $100 \mathrm{~m}$ for respondents that pictured the shopping scenario. Respondents of both groups showed a great willingness to pay for a smaller shift of departure with $3.47 \mathrm{cent} / \mathrm{min}$ for the shopping trip and $5.52 \mathrm{cent} / \mathrm{min}$ for the trip to a doctor's appointment. The high importance of the attribute travel time for the participants in the doctor's scenario is reflected by a higher WTP for a reduction in travel time (4.80 cent/ min) compared to the shopping trip (2.86 cent/min). Respondents further showed great willingness to pay for receiving more information on the ridepooling's trip details with only slight differences between the two trip purposes (20.16 cent/level for the shopping scenario and 21.28 cent/level for the doctor's appointment).

\section{Discussion}

\subsection{Summary and interpretation of findings}

This research was conducted in order to fill the research gap with regard to the limited empirical findings concerning travelers' preferences and needs related to ridepooling service concepts. The study builds upon and extents the recent study of König et al. [13] by broadening the focus and applying a regression modelling approach. Furthermore, the study adds onto the prior study by calculating willingness to pay values.

To conclude, all of the six service attributes proved to affect the respondents' appraisal of the ridepooling system. The model reveals that low fares, a small shift of departure and much information played a major role in the perceived utility of ridepooling services. The importance of a shift of departure further increases when the trip purpose was a fixed doctor's appointment. The model reveals that the utility of the ridepooling system decreases if the value of the service attributes increases, except the attribute information provision. The provision of more detailed information on the ride could thus be used to compensate the effect of a longer travel time or a higher shift of departure among others.

The attribute fare revealed a strong impact on the respondents' choice. Apparently, travelers attach high importance to low fares, thus confirming findings in the field of ridesharing that show cost savings to be one of the most influential attributes for using ridesharing [45]. The results are further in line with the findings of König et al. [13] that proved the high importance of price for urban residents' appraisal of ridepooling systems. The trip purpose had no significant effect on the respondents' appraisal of the attribute fare.

The importance of the service characteristic walking distance to access point was emphasized before in research concerning carpooling [46]. Accordingly, respondents showed a high willingness to pay for a gain in comfort due to a reduction of walking distance to the pick-up point. The results thus underline the relevance of a door-to-door service which can be a unique selling point of ridepooling services in comparison to public transport serving bus stops. The survey participants' willingness to pay for a reduction in walking distance was especially high when picturing a doctor's appointment. This finding is comprehensible in the light of the possible physical constraints that might be experienced when having a doctor's appointment.

The findings imply a high time sensitivity of respondents. A prolongation of the travel time due to the access and egress of fellow travelers was seen especially critical by respondents that were asked to picture a doctor's appointment as trip purpose as shown by a high willingness to pay for a reduction in travel time. The

Table 5 Willingness to pay (WTP) estimation of the five non-monetary attributes according to trip purpose

\begin{tabular}{|c|c|c|c|c|c|c|}
\hline & & \multicolumn{5}{|l|}{ Attribute } \\
\hline & & $\begin{array}{l}\text { Walking distance } \\
(\text { cent } / \mathrm{m})\end{array}$ & $\begin{array}{l}\text { Time of booking } \\
\text { (cent/min) }\end{array}$ & $\begin{array}{l}\text { Shift of departure } \\
\text { (cent/min) }\end{array}$ & $\begin{array}{l}\text { Travel time } \\
\text { (cent/min) }\end{array}$ & $\begin{array}{l}\text { Information provision } \\
\text { (cent/level) }\end{array}$ \\
\hline \multirow[t]{2}{*}{ Trip purpose } & Shopping & 0.09 & 0.60 & 3.47 & 2.86 & 20.16 \\
\hline & Doctor & 0.16 & 0.47 & 5.52 & 4.80 & 21.28 \\
\hline
\end{tabular}


findings underline the relevance of a fast ridepooling service, indicating that passengers would react very sensitive to long detours and would be willing to pay an extra amount of money in order to arrive punctually at appointments. In order to gain a wider acceptance of the flexible service concept of ridepooling systems further research should thus address the question which extent of roundabout way is acceptable depending on trip purpose and sociodemographic characteristics among others. Furthermore the finding underlines the relevance of a comprehensible real-time information provision to enhance service transparency and travelers' perception of control since the negative appraisal of a prolongation of travel time due to roundabout ways might be linked to an information deficit and a lack of traceability.

The service characteristic time of booking did as well affect the respondents' appraisal. It was shown that travelers value on-demand booking and are willing to pay for reducing the lead time of bookings. The analysis of interaction effects found no significant effect of trip purpose on the respondents' appraisal of the service attribute booking time.

The study further stressed the importance of the attribute information for the respondents' appraisal of the system. Since the flexibility and dynamic of the service concept are system inherent features of ridepooling services the need for a comprehensive information provision about the current trip increases compared to fixed scheduled public transport. It is likely to assume that an extensive information provision increases predictability of the service and thus enhance travelers' certainty and perceived control. Future research should examine the quality and quantity of information necessary to inform travelers about the operational concept in general as well as details of the current ride (e.g. route, arrival time, number of passengers boarding the vehicle).

Respondents seem to be highly sensitive to shifts of departure of the ridepooling systems that are caused by the previously entry or exit of other passengers. Shift of departure revealed a significant impact on the respondents' choice behavior in a way that the utility of a ridepooling service decreases if the departure time was postponed. Accordingly, they expressed a high willingness to pay for avoiding shifts of departure time. Further, a shift of departure seems to be of particular relevance when having a fixed appointment as indicated by the high WTP for a reduction in the extent of a shift of departure for the participants introduced to the doctor's scenario. Yet, timely flexibility is an inherent system characteristic of ridepooling schemes. Thus, a shift of departure and a detour are no exceptional cases of ridepooling operation but represent a usual case. Therefore, comprehensive explanations and information on the operational concept can be seen as a critical part for the users' acceptance of the ridepooling system. Furthermore, travelers should be informed preferably on time about changes of the departure or arrival of the transport system, once again underlining the importance of the attribute information. If ridepooling systems do not provide sufficient real-time information on the trip details, especially on the shift of departure and arrival a low acceptance of the innovative mobility form will be the result. In particular, travelers' willingness to use ridepooling systems for trips with a fixed date, like a job meeting, would presumably be low if the shift of departure and arrival would be too large. Thus, if ridepooling systems are expected to be used for a great variety of trip purposes extensive research on the timely and spatial dynamics of the service as well as the provision of information to facilitate the understanding and acceptance is needed.

To sum up, the results demonstrate that the credo "people will always favor the fastest transport mode unless it is more expensive than others" ([47], p. 1) is not necessarily applicable to the field of ridepooling services. Instead, travelers proved to be willing to pay for an improvement of service quality in terms of a shorter walk, an on-demand booking or a limitation of detour. The interpretation of the results implies that results regarding bus public transport cannot be simply transferred to the field of ridepooling but comprehensive research is needed in order to examine travelers' appraisal of ridepooling schemes.

\subsection{Limitations and further research needs}

It must be noted that the power of a Discrete Choice Experiment heavily relies on the selection of the attributes and levels. It is reasonable to assume that the extensive literature review and the focus group reduced the risk of an incorrect selection of attributes. Yet, it should be noted that the selection of attributes and their levels affected the model and the inclusion of further attributes, like attributes concerning the invehicle environment would possibly affect the model. Accordingly, the inclusion of sociodemographic variables like age or income would most likely influence the effects of the attributes on the travelers' appraisal of the ridepooling service. The authors thus see an important need for studying the effects of sociodemographic characteristics on the travelers' appraisal of ridepooling service characteristics.

Furthermore, it should be emphasized that the scope of the findings is limited to the chosen scenarios. The results described are thus restricted to the two trip purposes concerning a doctor's visit and a shopping trip in an urban setting. Further research could assess whether the findings are transferable to other trip types, like regular commuting trips. Presumably, the trip purposes 
will have a strong impact on the model and the willingness to pay.

Undoubtedly, the representativeness of the online survey participants must be questioned. A common limitation of online surveys lies in the self-selection of participants. To name one bias, the sample consisted of a lower share of participants that are aged above 65 years $(16.6 \%)$ than in the German population $(21 \%$ in 2016 according to the [48]). Furthermore the sample consisted of a higher share of well-educated people than the overall German population. For example, $53.7 \%$ of the respondents held an academic degree whereas the share in the German population is $16.5 \%$ [49]. The presented results thus cannot be simply inferred to the population but should be interpreted within the scope of the study's context and under consideration of the specific characteristics of the sample. The results need further validation in real-world experiments and field studies. Besides the analysis of sociodemographic characteristics of the respondents on the appraisal of the ridepooling's service attributes, the authors recommend modelling the effect of mobility behaviour and routines as well as prior conditions, like car ownership in further studies since habits have proven to play an important role for decision making and transport choices [12].

Since the description of the service concept and the attributes is seen as a critical part of the study as respondents need to understand the meaning of the attributes for assessing them, online surveys face the challenge of adequately imparting knowledge and gaining understanding. It is questionable if all participants understood the service concept of ridepooling and the description of the service attributes. For this reason, over $20 \%$ of the respondents were excluded from data analysis because of reading the introduction pages to fast. Yet, the study did not check whether the respondents really understood the meaning of the attributes. For instance, it is not possible to make a statement on the question whether the respondents understood the meaning of the attributes booking time and shift of departure as those are not common service characteristics of regular public transport modes that operate based on fixed lines and schedules.

\subsection{Recommendations for public transport operators and transport authorities}

Based on the findings, several theses can be derived that aim to adapt ridepooling service concepts to the needs of the travelers and thus might contribute to a more favorable appraisal of the transport system. Hence, when planning to launch a new ridepooling system the following recommendations should be considered in order to create and operate a ridepooling system that takes travelers' requirements into account.

- Overall travel time should be kept short by defining a maximum detour factor caused by roundabout ways.

- If possible, offer a door-to-door service to minimize walking distance to the pick-up point.

- Exploit opportunities based on digitalization to provide real-time booking opportunities that enable on demand mobility rather than long lead times for bookings.

- Shifts of departure time and changes in travel time are system inherent characteristics of ridepooling concepts and should be communicated as such to the users to ensure user acceptance.

- Travelers should be informed on time about changes in the departure or arrival of the ridepooling system using digital real time information systems on board and in a mobile application to avoid mistrust and disappointment about the ridepooling system.

- Avoid shifts of departure time shortly before the start of the ride by freezing the time window for bookings several minutes before the execution of a ride.

- The price could be adapted to the service quality of the offered ride in terms of low walking distance and few roundabout ways among others.

- Provide the possibility for the user to limit the maximum detour, respectively the latest time of arrival to ensure the timely meeting of appointments.

- Provide a customizable booking app that enables the configuration of individual preferences, e.g. the quantity of information provided about the trip.

\section{Conclusions}

In conclusion, the results of the study provide insight into the subjective relevance of factors that affect the users' appraisal of digitalized ridepooling characteristics since findings concerning fixed-scheduled public transport cannot merely be transferred to ridepooling concepts due to their system inherent dynamic of service. The results of the Discrete Choice Experiment show that respondents prefer short walking distances and react sensitive to a prolongation of travel time. Furthermore, the overall utility value increases as more information is provided. The utility of a ridepooling service decreases if the departure time is postponed and the operation requires higher lead times for booking. As expected, trip purpose affected the choice behavior in a way that respondents assessed the service characteristics differently depending on the trip purpose. The results give guidance for 
the creation of a user-centered public transport system that meets the requirements of the prospective passengers and thus might contribute to the adoption of such shared digitalized transport systems. Further research should consider sociodemographic effects on the appraisal of the service attributes of ridepooling and consider further trip purposes and the possible interplay with sociodemographic characteristics.

\section{Abbreviations}

AIC : Akaike Information Criterion; DCE: Discrete Choice Experiment DRT: demand-responsive transport; MMNL: Mixed Multinominal Logit; RUT: Random Utility Theory; WTP: Willingness to pay

\section{Acknowledgements}

The authors would like to thank the student Tabea Bonus for her support in the data collection process.

\section{Authors' contributions}

AK prepared the idea and the research gap, carried out the literature review and the focus group, designed and carried out the DCE and analyzed the results. JG contributed in designing the DCE, derived the recommendations and contributed in writing the article. Both authors read and approved the final manuscript.

\section{Funding}

This research was funded by DLR's programmatic research funds as part of the Helmholtz Association.

\section{Availability of data and materials}

The datasets collected and analyzed in the study are not publicly available because of some personal data included in database but are available from the corresponding author on reasonable request.

\section{Competing interests}

We have no conflicts of interest to disclose.

We confirm that neither the manuscript nor any parts of its content are currently under consideration or published in another journal.

Received: 3 April 2019 Accepted: 11 December 2019

Published online: 31 December 2019

\section{References}

1. OECD (2017). ITF transport outlook 2017, Paris, France: OECD Publishing http://dxdoi.org/101787/9789282108000-en Accessed 25 Mar 2019.

2. Feigon, S. \& Murphy, C. (2016). Shared Mobility and the Transformation of Public Transit. TCRP Report 188. DOI: https://doi.org/10.17226/23578

3. Alonso-Mora, J., Samaranayake, S., Wallar, A., Frazzoli, E., \& Rus, D. (2017). Ondemand high-capacity ride-sharing via dynamic trip-vehicle assignment. Proceedings of the National Academy of Sciences, 114(3), 462-467.

4. Fagnant, D. J., \& Kockelman, K. M. (2014). The travel and environmental implications of shared autonomous vehicles, using agent-based model scenarios. Transportation Research Part C: Emerging Technologies, 40, 1-13.

5. Jain, S., Ronald, N., Thompson, R., \& Winter, S. (2017). Predicting susceptibility to use demand responsive transport using demographic and trip characteristics of the population. Travel Behaviour and Society, 6, 44-56.

6. Shaheen, S. \& Cohen, A. (2018). Shared Mobility Policy Briefs: Definitions, Impacts, and Recommendations. UC Berkeley ITS reports No. UC-ITS-RR2017-11. https://doi.org/10.7922/G27S7KX6.

7. OECD (2014). International experiences on public transport provision in rural areas. Paris: International transport forum. https://www.itf-oecd.org/ sites/default/files/docs/15cspa_ruralareas.pdf accessed 05 Feb 2019.

8. Savelberg, F.; Moorman, S. \& Bakker, P. (2017). Conditions for success in public transport innovations. Paper presented at the 47th European transport conference, Barcelona, Spain, October 2017

9. Jokinen, J.-P., Sihvola, T., \& Mladenovic, M. N. (2017). Policy lessons from the flexible transport service pilot Kutsuplus in the Helsinki capital region. Transport Policy (in press) https://doi.org/10.1016/j.tranpol.2017.12.004.
10. ioki GmbH (2019, July 16). Inspiring Smart Mobility. ioki Homepage https:// ioki.com/ Accessed 05 Mar 2019.

11. Clewlow, R. (2016). Shared-Use Mobility in the United States: Current Adoption and Potential Impacts on Travel Behavior. Paper presented at the Transportation Research Board 95 ${ }^{\text {th }}$ Annual Meeting, 10.-14-Jan. 2016, Washington, D.C.

12. Tsafarakis, S., Gkorezis, P., Nalmpantis, D., Genitsaris, E., Andronikidis, A., \& Altsitsiadis, E. (2019). Investigating the preferences of individuals on public transport innovations using the maximum difference scaling method. European Transport Research Review, 11(3). https://doi.org/10.1186/s12544018-0340-6.

13. König, A., Bonus, T., \& Grippenkoven, J. (2018). Analyzing urban residents' appraisal of ridepooling service attributes with conjoint analysis. Sustainability, 10(10), 3711 https://doi.org/10.3390/su10103711.

14. Beirão, G., \& Cabral, J. A. S. (2007). Understanding attitudes towards public transportation and private car: A qualitative study. Transport Policy, 14, 478489 https://doi.org/10.1016/j.tranpol.2007.04.009.

15. Bourgeat, P. (2015). A revealed/stated preference approach to bus service configuration. Transportation Research Procedia, 6, 411-442. https://doi.org/ 10.1016/j.trpro.2015.03.031

16. Dell'Olio, L., Ibeas, A., \& Cecin, P. (2011). The quality of service desired by public transport users. Transport Policy, 18, 217-227 https://doi.org/10.1016/j. tranpol.2010.08.005.

17. De Oña, J., De Oña, R., Eboli, L., \& Mazzulla, G. (2013). Perceived service quality in bus transit service: A structural equation approach. Transport Policy, 29, 219-226 https://doi.org/10.1016/j.tranpol.2013.07.001.

18. De Oña, J., de Oña, R., Eboli, L., Forciniti, C., \& Mazzulla, G. (2016). Transit passengers' behavioural intentions: The influence of service quality and customer satisfaction. Transportmetrica A: Transport Science, 12(5), 385-412 https://doi.org/10.1080/23249935.2016.1146365.

19. Diab, E., van Lierop, D., \& El-Geneidy, A. (2017). Recommending transit. Disentangling users' willingness to recommend transit and their intended continued use. Travel Behaviour and Society, 6, 1-9 https://doi.org/10.1016/j. tbs.2016.03.001.

20. Eboli, L., \& Mazzulla, G. (2008). A stated preference experiment for measuring service quality in public transport. Transportation Planning and Technology, 31(5), 509-523 https://doi.org/10.1080/03081060802364471.

21. Hansson, J., Pettersson, F., Svensson, H., \& Wretstrand, A. (2019). Preferences in regional public transport: A literature review. European Transport Research Review, 11, 38 https://doi.org/10.1186/s12544-019-0374-4.

22. Hensher, D., \& Prioni, P. (2002). A service quality index for area-wide contract performance assessment. Journal of Transport Economics and Policy, 36, 93113. https://doi.org/10.1016/S0739-8859(06)18014-2.

23. Jianrong, L., Wei, D., \& Bing, Z. (2011). Conjoint analysis based transit service quality research. Journal of Transportation Systems Engineering and Information Technology, 11, 97-102.

24. Paulley, N., Balcombe, R., Mackett, R., et al. (2006). The demand for public transport: The effects of fares, quality of service, income and car ownership. Transport Policy, 13(4), 295-306 https://doi.org/10.1016/j. tranpol.2005.12.004

25. Redman, L., Friman, M., Gärling, T., \& Hartig, T. (2013). Quality attributes of public transport that attract car users: A research review. Transport Policy, 25, 119-127 https://doi.org/10.1016/j.tranpol.2012.11.005.

26. Tyrinopoulos, Y., \& Antoniou, C. (2008). Public transit user satisfaction: Variability and policy implications. Transport Policy, 15(4), 260-272 https:// doi.org/10.1016/j.tranpol.2008.06.002.

27. Tyrinopoulos, Y., \& Antoniou, C. (2012). Factors affecting modal choice in urban mobility. European Transport Research Review, 5(1), 27-39 https://doi. org/10.1007/s12544-012-0088-3

28. Mazzulla, G., \& Eboli, L. (2006). A service quality experimental measure for public transport. European Transport, 34, 42-53.

29. Gim, T. H. T. (2018). SEM application to the household travel survey on weekends versus weekdays: The case of Seoul, South Korea. European Transport Research Review, 10(11). https://doi.org/10.1007/s12544-018-0285-9.

30. Steck, F., Kolarova, V., Bahamonde-Birke, F., Trommer, S., \& Lenz, B. (2018). How autonomous driving may affect the value of travel time savings for commuting. Transp Res Rec J Transp Res Board, 2672(46), 11-20 https://doi. org/10.1177/0361198118757980.

31. Louviere, J. J., Flynn, T. N., \& Carson, R. T. (2010). Discrete choice experiments are not conjoint analysis. Journal of Choice Modelling, 3(3), 57-72 https://doi. org/10.1016/S1755-5345(13)70014-9. 
32. Kløjgaard, M. E., Bech, M., \& Søgaard, R. (2012). Designing a stated choice experiment: The value of a qualitative process. Journal of Choice Modelling, 5(2), 1-18.

33. Morrison, Mark D.; Bennett, Jeff W. \& Blamey, Russell K. (1997). Designing Choice Modelling Surveys Using Focus Groups: Results from the Macquarie Marshes and Gwydir Wetlands Case Studies. Choice Modelling Research Report No. 5, Canberra: The University of New South Wales. https://crawford. anu.edu.au/pdf/staff/jeff_bennett/chmdrr05.pdf Accessed 05 Mar 2019.

34. Weiber, R., \& Mühlhaus, D. (2009). Auswahl von Eigenschaften und Ausprägungen bei der Conjointanalyse. In D. Baier \& M. Brusch (Eds.), Conjointanalyse (pp. 43-58). Heidelberg: Springer.

35. Aizaki, H., Nakatani, T., \& Sato, K. (2015). Stated preference methods using R. Boca Raton: CRC Press.

36. Hair, J. H., Black, W. C., Babin, B. J., \& Anderson, R. E. (2010). Conjoint Analysis, In J. F. Hair, W. C. Black, B. J. Babin, \& R. E. Anderson (Eds.), Multivariate Data Analysis (pp. 341-414). Harlow, United Kingdom: Pearson Education.

37. Leiner, D.J. (2014). SoSci survey (version 2.5.00-i) [computer software]. Retrieved from https://www.soscisurvey.de accessed 01 Dec 2018.

38. Bahamonde-Birke, F. J., Navarro, I., \& de Dios Ortúzar, J. (2017). If you choose to not decide, you still have made a choice. Journal of Choice Modelling, 22, 13-23 https://doi.org/10.1016/j.jocm.2016.11.002.

39. McFadden, D., \& Train, K. (2000). Mixed MNL models for discrete response. Journal of Applied Econometrics, 15(5), 447-470.

40. Lancsar, E., Fiebig, D. G., \& Hole, A. R. (2017). Discrete choice experiments: A guide to model specification, estimation and software. Pharmacoeconomics, 35(7), 697-716 https://doi.org/10.1007/s40273-017-0506-4.

41. Sillano, M., \& de Dios Ortúzar, J. (2005). Willingness-to-pay estimation with mixed logit models: some new evidence. Environment and Planning, 37, 525-550. https://doi.org/10.1068/a36137.

42. R Development Core Team (2007). R: A language and environment for statistical computing. R Foundation for Statistical Computing, Vienna, Austria. http://www.r-project.org/. Accessed 13 Jan 2019.

43. Croissant, Y. (2012). Estimation of multinomial logit models in R: The mlogit packages. R package version 02-2 https://pdfssemanticscholarorg/8d40/ 143d338c298a4b5e6d421a730d54908c9ebapdf Accessed 13 Jan 2019.

44. Hole, A. R. (2007). Fitting mixed logit models by using maximum simulated likelihood. The Stata Journal, 7(3), 388-401.

45. Malodia, S., \& Singla, H. (2016). A study of carpooling behaviour using a stated preference web survey in selected cities of India. Transportation Planning and Technology, 39(5), 538-550 https://doi.org/10.1080/03081060. 2016.1174368

46. Wilkowska, W., Farrokhikhiavi, R., Ziefle, M. \& Vallèe, D. (2014). Mobility requirements for the use of carpooling among different user groups. Proceedings of the 5th AHFE conference, 19.-23. July 2014, 129-140.

47. Lenoir, N. \& Laplace, I. (2017). Beyond traditional value-of-time: Passenger behaviour for multimodal door-to-door travels in the age of information technologies. Paper presented at the 47th European transport conference, Barcelona, Spain, October 2017

48. Federal Institute for Population Research (2019). Bevölkerungsentwicklung. Anteile der Altersgruppen unter 20, ab 65 und ab 80 Jahre in Deutschland 1871 bis 2060 (Stand: 2016) https://wwwbibbundde/DE/Fakten/Fakt/B15Altersgruppen-Bevoelkerung-1871-Vorausberechnunghtml?nn=9991400 Accessed 22 July 2019.

49. Federal Office of Statistics (2019). Bildungsstand Bevölkerung im Alter von 15 Jahren und mehr nach allgemeinen und beruflichen Bildungsabschlüssen nach Jahren. https://www.destatisde/DE/Themen/ Gesellschaft-Umwelt/Bildung-Forschung-Kultur/Bildungsstand/Tabellen/ bildungsabschlusshtml. Accessed 22 July 2019

50. Eboli, L., \& Mazzulla, G. (2011). A methodology for evaluating transit service quality based on subjective and objective measures from the passenger's point of view. Transport Policy, 18(1), 172-181 https://doi.org/10.1016/j. tranpol.2010.07.007.

51. Knapp, F.D. (1998). Determinanten der Verkehrsmittelwahl. Abhandlungen zur Nationalökonomie 10, Duncker \& Humblot, Berlin.

\section{Publisher's Note}

Springer Nature remains neutral with regard to jurisdictional claims in published maps and institutional affiliations.

\section{Submit your manuscript to a SpringerOpen ${ }^{\circ}$ journal and benefit from:}

- Convenient online submission

- Rigorous peer review

- Open access: articles freely available online

High visibility within the field

- Retaining the copyright to your article

Submit your next manuscript at $\boldsymbol{\triangleright}$ springeropen.com 